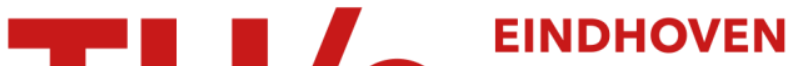

\section{Fibre-array pigtailing and packaging of an inp-based optical cross-connect chip}

Citation for published version (APA):

Zantvoort, van, J. H. C., Huijskens, F., Herben, C. G. P., \& Waardt, de, H. (1999). Fibre-array pigtailing and packaging of an inp-based optical cross-connect chip. IEEE Journal of Selected Topics in Quantum Electronics, 5(5), 1255-1259. https://doi.org/10.1109/2944.806749

DOI:

10.1109/2944.806749

Document status and date:

Published: 01/01/1999

\section{Document Version:}

Publisher's PDF, also known as Version of Record (includes final page, issue and volume numbers)

\section{Please check the document version of this publication:}

- A submitted manuscript is the version of the article upon submission and before peer-review. There can be important differences between the submitted version and the official published version of record. People interested in the research are advised to contact the author for the final version of the publication, or visit the $\mathrm{DOI}$ to the publisher's website.

- The final author version and the galley proof are versions of the publication after peer review.

- The final published version features the final layout of the paper including the volume, issue and page numbers.

Link to publication

\section{General rights}

Copyright and moral rights for the publications made accessible in the public portal are retained by the authors and/or other copyright owners and it is a condition of accessing publications that users recognise and abide by the legal requirements associated with these rights.

- Users may download and print one copy of any publication from the public portal for the purpose of private study or research.

- You may not further distribute the material or use it for any profit-making activity or commercial gain

- You may freely distribute the URL identifying the publication in the public portal.

If the publication is distributed under the terms of Article 25fa of the Dutch Copyright Act, indicated by the "Taverne" license above, please follow below link for the End User Agreement:

www.tue.nl/taverne

Take down policy

If you believe that this document breaches copyright please contact us at:

openaccess@tue.nl

providing details and we will investigate your claim. 


\title{
Fiber-Array Pigtailing and Packaging of an InP-Based Optical Cross-Connect Chip
}

\author{
Johan H. C. van Zantvoort, Frans M. Huijskens, Chretien G. P. Herben, and Huig de Waardt
}

\begin{abstract}
A method of coupling six single-mode fiber tapers with $250-\mu \mathrm{m}$ spacing to an InP-based integrated optical crossconnect chip has been developed and realized. The complete pigtailed chip assembly is packaged while chip temperature can be controlled. The device is successful tested at an ambient temperature range of $5^{\circ} \mathrm{C}$ to $45^{\circ} \mathrm{C}$.
\end{abstract}

Index Terms - Coupling efficiency, fiber-array, integrated optics, PHASAR, tapered fibers, thermoelectric device, wavelengthdivision multiplexing (WDM).

\section{INTRODUCTION}

$\mathbf{T}$ HE DIMENSIONS of a planar waveguide structure determine the degree of difficulty of pigtailing a singlemode fiber (SMF) to such a planar waveguide structure. If the dimensions of the waveguide match the mode field of an optical fiber, standard butt coupling can be used. The optical cross-connect chip [1] is processed on InP. Advantages of this material are the high refractive index, so compact components can be made, and active components can be integrated. Disadvantage is a high coupling loss between the smaller monomode waveguide and a single-mode optical fiber. To reduce those losses, selected tapered lensed fibers are used to fabricate a perfect fiber-array to couple infrared light in the optical cross-connect chip by two input fibers and out by two output fibers. All components of the package are fixed with adhesive. The chip, which can cross connect signals at four wavelengths independently from the input fibers to the output fibers, has been realized by integrating polarization dispersion compensated $16 \times 16$ PHASAR with four electrooptical Mach-Zehnder interferometer (MZI) switches. The dimensions of the chip are $7 \times 9 \mathrm{~mm}^{2}$.

\section{DESIGN}

The coupling construction, as depicted in Fig. 1, consists basically of three elements:

- An invar base plate with a flexible part formed by a singular elastic hinge (1). The position of the flexible part can be controlled by means of piezo translators which are connected to it by the three removable displacement pins

Manuscript received December 28, 1998; revised April 16, 1999. This work was supported in part by the ACTS AC-065 Project BLISS and ACTS AC332 Project APEX.

J. H. C. van Zantvoort, F. M. Huijskens and H. de Waardt are with the Technical University of Eindhoven, Faculty of Electrical Engineering, Electrooptical Communication EH-12, 5600 MB Eindhoven, The Netherlands.

C. G. P. Herben is with the Delft University of Technology, Faculty of Information Technology and Systems, Photonic Integrated Circuits Group, NL-2600 GA, Delft, The Netherlands.

Publisher Item Identifier S 1077-260X(99)07921-6.

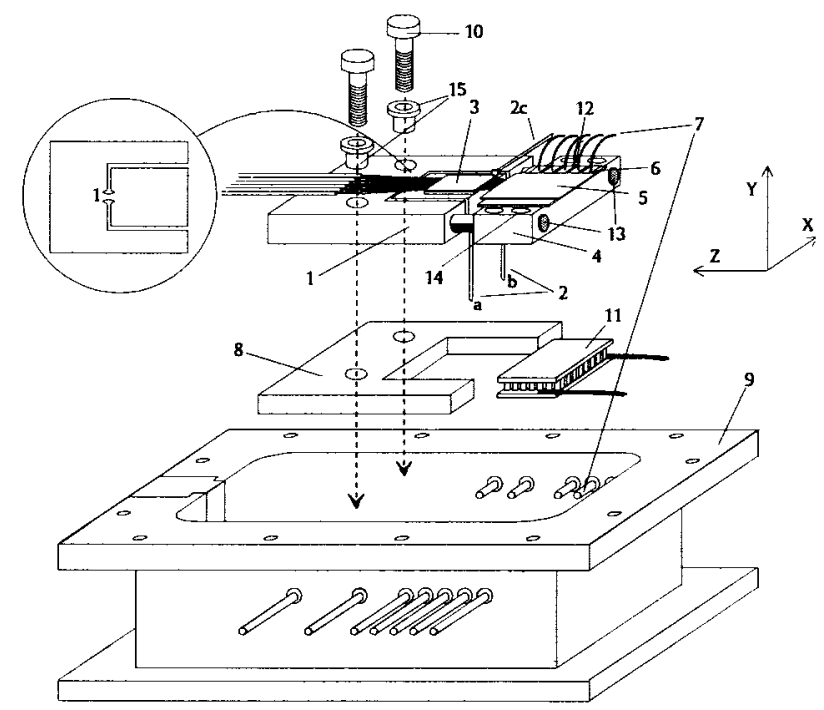

Fig. 1. Package and fiber-array to optical cross-connect chip coupling construction.

$2 \mathrm{a}, \mathrm{b}$, and c. Pins $2 \mathrm{a}$ and $\mathrm{b}$ tilt and roll the flexible part in the vertical $y$-direction, pin $2 \mathrm{c}$ moves it in the horizontal $x$-direction.

- A silicon V-groove with mounted selected tapered fibers in an array placed on the flexible part (3). We used lensed tapered fibers to convert the circular mode field of the SMF to the small elliptical mode field of the planar waveguides (actual waveguide dimensions are $3 \mu \mathrm{m}$ in the $x$-direction and $0.6 \mu \mathrm{m}$ in the $y$-direction) of the optical cross-connect chip.

- An invar carrier (4) for the optical cross-connect chip (5) that can be shifted toward the fiber-array until the optimal distance between fiber-tips and optical waveguides is reached. The chip is mounted on an aluminum nitride (AlN) substrate (6) that has a $2-\mu \mathrm{m}$ gold layer where electrical paths and bondpads are etched. The function of this submount is to connect the four integrated MZI switches of the cross-connect with isolated electrical feedthroughs (7). The AlN-substrate also conducts heat from or to the chip very well.

After optimal alignment of the fiber-array in front of the desired in- and output waveguides of the optical cross-connect chip, the flexible part is fixed to the base plate with adhesive. The three displacement pins $2 \mathrm{a}, \mathrm{b}$, and $\mathrm{c}$ are removed and the system is mounted on a flat aluminum-oxide $\left(\mathrm{Al}_{2} \mathrm{O}_{3}\right)$ support profile (8) in an aluminum package (9) with two screws (10). The aluminum-oxide support profile is placed to provide mechanical stability. The thermoelectric cooler (11) 

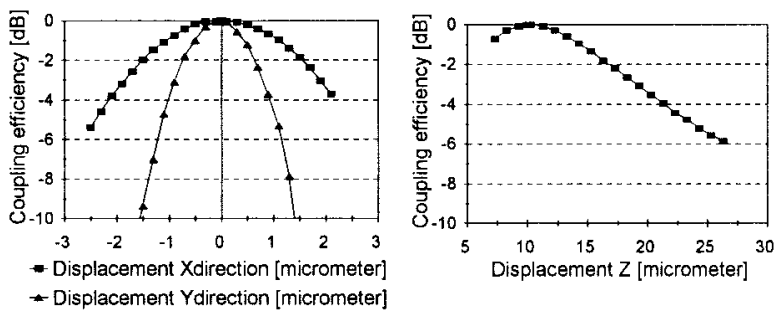

Fig. 2. Normalized fiber to chip coupling efficiencies for various displacements.

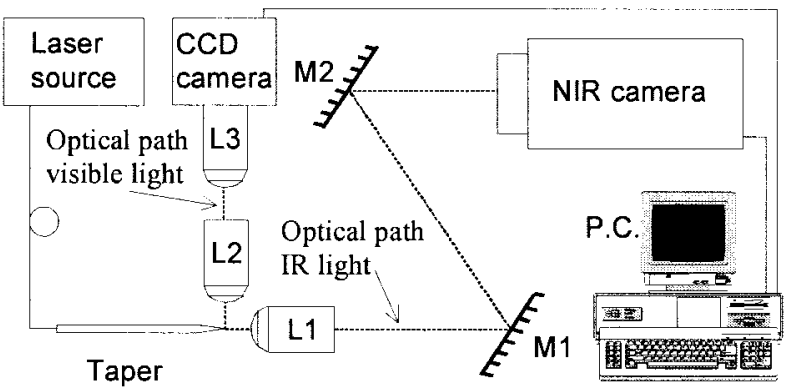

Fig. 3. Lens eccentricity measurement setup.

is placed under the carrier part to tune the PHASAR of the optical cross-connect to the target wavelengths of $1551.1 \mathrm{~nm}$, $1554.2,1557.4$, and $1560.6 \mathrm{~nm}$. A $10-\mathrm{k} \Omega$ impedance NTC thermistor (12) is mounted near the chip in the invar carrier part and measures the local chip temperature. To avoid water condensation at low temperature of the chip, the package is hermetically closed and filled with dry nitrogen.

\section{Assembly of DeVICE}

\section{A. Assembly of Fiber-Array}

The SMF tapers we used have a 0.9-mm buffer, which has been removed over a length of $25 \mathrm{~mm}$ from the fiber tip. The taper angle lies between $50^{\circ}$ and $55^{\circ}$ and the lens radius of the taper is $14 \pm 2 \mu \mathrm{m}$. The tapers are AR coated for $1550 \mathrm{~nm}$. The lens eccentricity, however, is smaller than $2 \mu \mathrm{m}$. This means that if the fiber tip is not exactly matching the optical axis of the fiber core, then the focussed light spot is deflected from the optical axis. We have measured the increase of coupling efficiency as a function of the displacement of the fiber tip in the $x, y$, and $z$ direction. In Fig. 2, the relative coupling losses due to misalignment of a single tapered fiber in front of an InP-waveguide are shown. The vertical direction, which is indicated with $y$-direction, is most sensitive to displacement. Before we assemble the fiber-array, we must first know which fibers have almost the same eccentricity and in which direction the focussed spotlight is deflected. The fibers must be rotated in such a way that the position of the focussed spot formed by each fiber tip lies in the same horizontal plane for all six fibers. A schematical set-up for the measurement of the lens eccentricity is given in Fig. 3. The fiber taper is rotated $360^{\circ}$ in steps of $45^{\circ}$ in a silicon $\mathrm{V}$-groove and carefully pushed in the $\mathrm{V}$-groove by a clamp. The fiber is launched with laser light and the infrared spot formed by the lensed taper is imaged by an objective L1 and mirrors M1 and M2 on an infrared camera (NIR camera), which is connected to a personal computer with

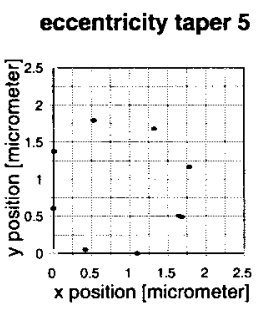

(a)

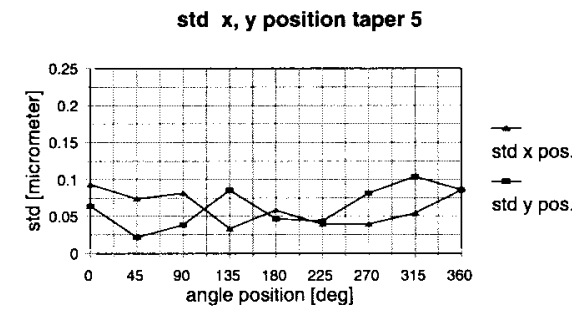

(b)
Fig. 4. Measured results of taper eccentricity. (a) Relative IR spot position in the $x y$ plane as a function of the mecahnical rotation of the fibertip. (b) The population standard deviation of eight observations for each mechanical angle position of the fibertip.

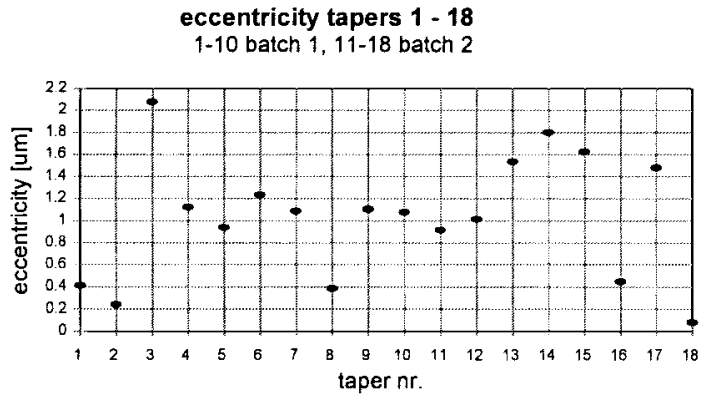

Fig. 5. Measured eccentricity of tapered fibers.

frame grabber. Mirrors M1 and M2 are used to get a long image distance for a high magnification of the infrared spot from the tapered fiber tip. The lens system L2 and L3 images the magnified fiber tip on a CCD camera. This image is stored in a file and will be compared with the actual image after the fiber tip is rotated $45^{\circ}$ and pushed down in the V-groove. Both images (the stored one in a file and the actual one) are subtracted from each other to check the mechanical position of the fiber tip with his previous position. If the mechanical position of the fiber tip is the same, a possible change of the IR spot on the NIR camera caused by the lens eccentricity of the fiber tip can be measured. The absolute IR spot position on the NIR camera and the orientation of fiber tip $\left(0^{\circ}, 45^{\circ}\right.$, $90^{\circ}, 135^{\circ}, 180^{\circ}, 225^{\circ}, 270^{\circ}, 315^{\circ}$, and $360^{\circ}$ ) are measured and registered. Every mechanical position of the fiber tip is measurement random eight times.

In Fig. 4 is given an example of a measurement of one taper. In Fig. 4(a) the relative IR spot position in the $x-y$ plane as a function of the mechanical rotation (in steps of $45^{\circ}$ ) is shown. In Fig. 4(b) the population standard deviation (std) of eight observations for each mechanical angle position in the $x$ direction (std $x$ pos.) and $y$ direction (std $y$ pos.) is given. So the relative IR spot position in the first figure has an accuracy better than $0.1 \mu \mathrm{m}$. The eccentricity of the tapered fiber is equal to the radius of the imaginary circle of the relative IR spot position movement as a function of the mechanical rotation of the tapered fiber tip. The eccentricity of the mentioned taper in Fig. 4 is $0.9 \pm 0.1 \mu \mathrm{m}$. This measurement has been done for 18 tapered fibers. The tapers are labeled and the direction of eccentricity is marked. Typical measured values are shown in Fig. 5. The average measured eccentricity is $1 \mu \mathrm{m}$. 
The commercially available silicon $\mathrm{V}$-groove substrate used to assemble the fiber array has a pitch of $250 \pm 0.5 \mu \mathrm{m}$. The $\mathrm{V}$-groove substrate is aligned perpendicularly to the front of the flexible part of the base plate. The upper surface of the base plate is partly roughened with small milled grooves. Low viscosity adhesive is used to fixate the $\mathrm{V}$-groove profiting the capillary effect. The base plate is placed in a mechanical setup. The selected fibers are put in the V-grooves one by one and simultaneously pushed down when the deflection of the IR spot caused by the lens eccentricity of the tapered fibers are in the same vertical $y$-direction. The fibers are adjusted in the $z$-direction by carefully pushing back all the fiber tips together by means of a flat glass plate, mounted on a piezo translator. The fibers are enclosed in the grooves with a cover glass and adhesive is added. Deviation of the focus points due to slightly different fiber tip curvature radii does not effect the coupling efficiency in the $z$-direction seriously, as this direction is rather insensitive. The 0.9-mm buffers are glued to the rear part of the base plate to provide extra strain relief. The IR spot positions formed by the lensed fibers of the fiber-array when they are launched with laser light, can be measured by an imaging system. This consists of a taper with low eccentricity, which is connected with a power meter and is mounted on a $x, y$, and $z$ piezo stage. If the maximum power is measured, the $x, y$, and $z$ coordinates correspond with the absolute spot position of the concerned taper. A measured eccentricity IR spot distribution of less than $0.5 \mu \mathrm{m}$ is observed.

\section{B. Assemble of Fiber-Array and OXC Chip}

The optical cross-connect is fixed on a $254-\mu \mathrm{m}$ thick AlNsubstrate. The integrated electrooptical MZI switches on the chip are bonded with bondpads on the AlN-substrate. This system is placed on the invar carrier and temporary held in position using a vacuum hole in the middle of this part. The chip is visually aligned adjusting the in- and output waveguides to be parallel and opposite to the six fiber tips. The submount is permanently attached on the carrier by using low viscosity adhesive. The carrier can be shifted toward the fiber array on the base plate until the optimal distance between fiber tip and optical waveguide is reached. This distance is $10-12 \mu \mathrm{m}$ (Fig. 2). The two sliding bars (Fig. $1 \mathrm{nr}$. 13) provide a parallel movement. Previous these rods are already tightly fitted to the base plate. The invar carrier is fixed to these rods by 4 holes on the border (Fig. $1 \mathrm{nr}$. 14). The influence of the shrinking effect in the $z$-direction of the epoxy during curing is minimized as the forces in this direction are avoided as a consequence of the perpendicular direction of the holes to the rod. Alignment of the fiber array is carried out with help of the two auxiliary fibers at the extremes of the array. The infrared light from these fibers is launched in two waveguides on the cross-connect chip used as alignment waveguides. At the rear side of the chip these infrared spots are monitored by an objective lens on an infrared camera. The inner four fibers are designated to the input and output channels of the cross-connect. These are also used for fine-adjustment. The excess loss is measured during alignment and fixation. The flexible part is fixed to the base plate with low shrinking

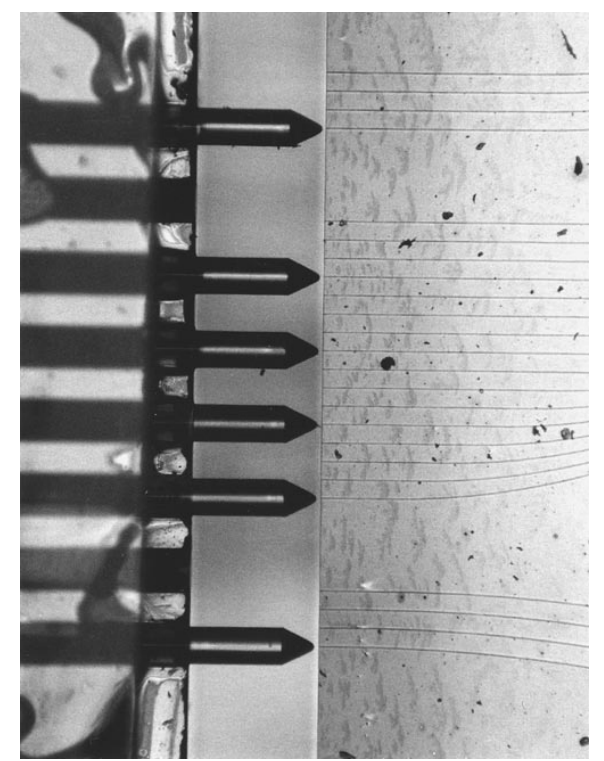

Fig. 6. Fiber-array optical cross-connect chip section.

adhesive. The next step is to attach five electrical wires (four for the optical switches and one for the ground connection) to the bond-pads on the ALN-substrate using electrically conductive, silver-filled epoxy paste. Curing is possible at room temperature. Finally, the three displacement pins are removed. The complete assembly is then ready to be mounted in a package.

\section{Assemble of Fiber-Array Chip System in Package}

A thermoelectric cooler with a heat pumping capacity of $3.2 \mathrm{~W}$ is mounted in an aluminum package and connected with electrical isolated feedthroughs. The aluminum-oxide support profile has exactly the same thickness as the thermoelectric cooler. The fiber-array chip system is mounted on those two parts by tightening two screws. To avoid heat transfer, two nylon isolating spacers (Fig. $1 \mathrm{nr} .15$ ) are mounted between the screws and the invar base plate. A $10-\mathrm{k} \Omega$ NTC thermistor is mounted in the invar carrier and also connected with two feedthroughs. The five electrical wires, used to operate the MZI switches, are connected to the outside with five feedthroughs. The integrated MZI switches have two connections, one is used for applied voltage and the other is used for backup if the other failed. In the package, five additional feedthroughs are mounted, which are reserved for the backup connection. The fibers are enclosed by an aluminum part (see Fig. 7). A precision O-ring located between the coverand upper-flange assures hermetic sealing after the package has been filled with dry nitrogen gas. The fiber pigtails are provided with FC/PC-type connectors.

\section{EXPERIMENTAL RESULTS}

The package is mounted on an aluminum bottom plate and connected with a printed circuit board. When the input ports are fed with a broadband source such as the spontaneous emission of an optical amplifier the output ports exhibits the transmission characteristics shown in Fig. 8. The chip temperature is set at $16{ }^{\circ} \mathrm{C}$, to tune the integrated PHASAR to 


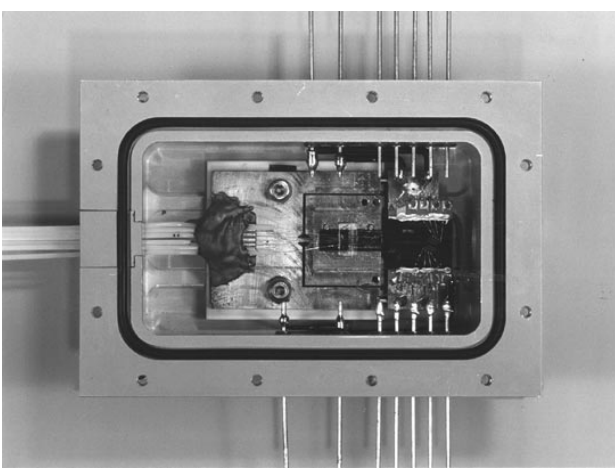

(a)

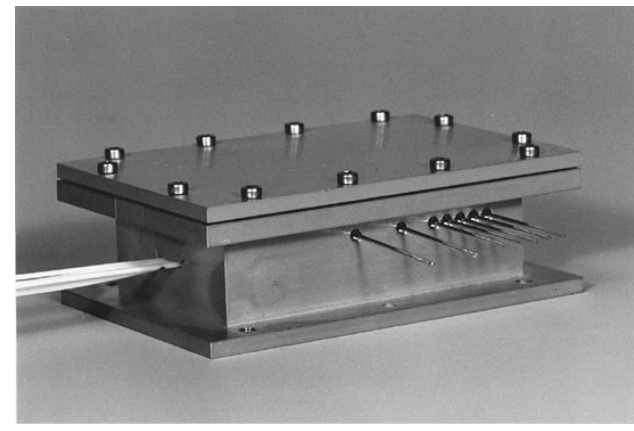

(b)

Fig. 7. The cross-connect chip in realized package. The package size is 81 $\times 56 \times 27 \mathrm{~mm}^{3}$.

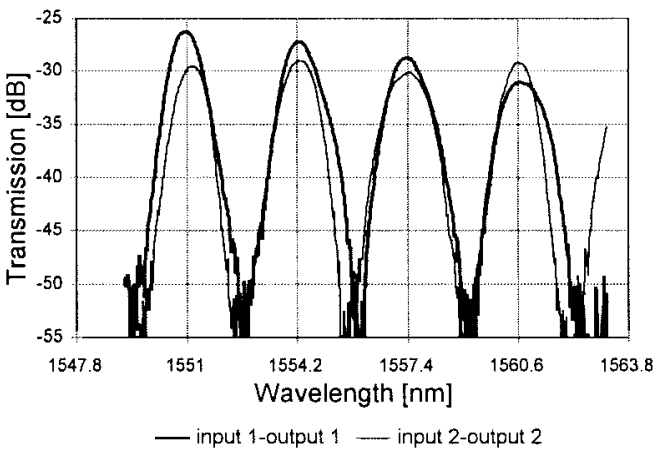

Fig. 8. Transmission characteristics of packaged cross connect.

the target wavelengths of 1551.1, 1554.2, 1557.4, and 1560.6 $\mathrm{nm}$. The excess losses of the input and output combinations lie (after polarization adjustment) between 24 and $27 \mathrm{~dB}$. Giving the estimated on chip loss $14 \pm 1 \mathrm{~dB}$, the average coupling loss caused by the fiber to chip coupling is $5 \mathrm{~dB}$. A best excess loss of $24 \mathrm{~dB}$ has been measured for the TE-mode. The cross-connect chip features a polarization dependence of approximately $3.1 \mathrm{~dB}$.

The transmission characteristics have been studied by varying the ambient temperature from $5^{\circ} \mathrm{C}$ to $45^{\circ} \mathrm{C}$ with driving and not driving the thermoelectric device. In Fig. 9, is given the relationship between ambient temperature and the transmission of the integrated PHASAR.

When the thermoelectric device is in the off state, the transmission wavelength of the PHASAR exhibit a temperature dependent shift in proportion to the ambient temperature of $0.12 \mathrm{~nm} /{ }^{\circ} \mathrm{C}$. When the thermoelectric device is in the on state, the target wavelengths can easily be matched at a chip

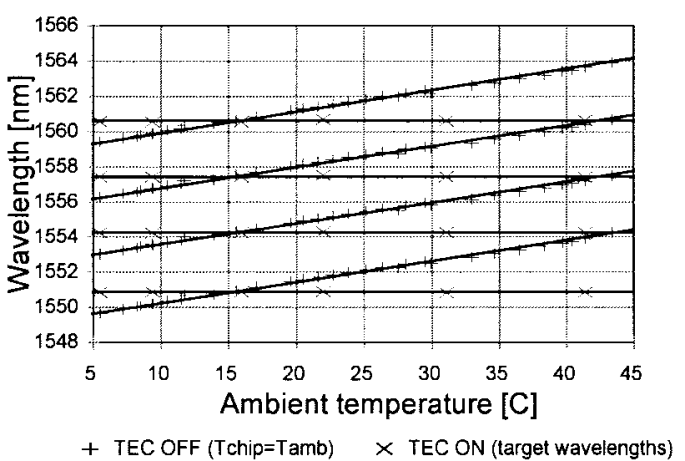

Fig. 9. Relationship between ambient temperature and transmission PHASAR

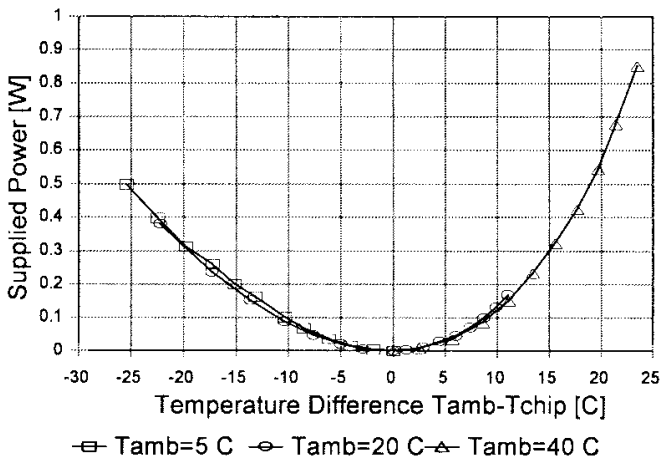

Fig. 10. Relationship between electrical power and temperature difference Tamb-Tchip.

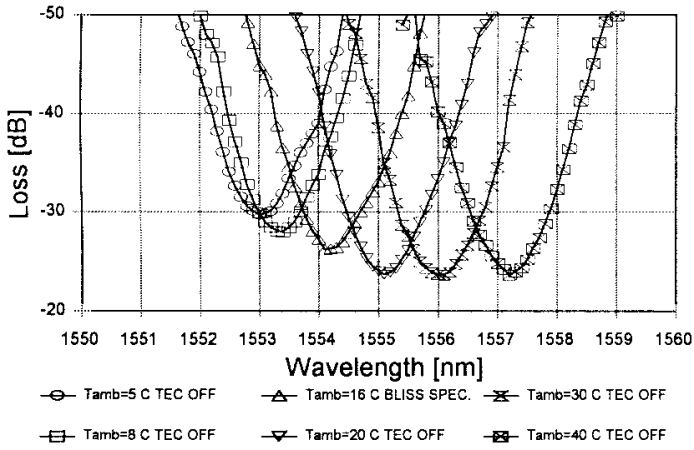

Fig. 11. Relationship between transmission curve of second wavelength channel and ambient temperature.

temperature of $16{ }^{\circ} \mathrm{C}$. The electrical power to control the chip temperature depends on the temperature difference between ambient temperature and chip temperature (Fig. 10). At three ambient temperatures of $5{ }^{\circ} \mathrm{C}, 20^{\circ} \mathrm{C}$, and $40^{\circ} \mathrm{C}$ the chip temperature is varied. With an electrical power of less than $1 \mathrm{~W}$, the chip temperature can be cooled down with $25^{\circ} \mathrm{C}$ or heated up with $25^{\circ} \mathrm{C}$. This implies that the heat leakage from the invar carrier to the invar base plate, by means of the two rods and the aluminum oxide carrier, is minimal.

In Fig. 11, an example is given from the second wavelength channel of $1554.2 \mathrm{~nm}$ as a function of the ambient temperature. The polarization is optimized for TE mode. In the temperature range from $20^{\circ} \mathrm{C}$ to $40{ }^{\circ} \mathrm{C}$, the total excess losses remain constant at $23.7 \mathrm{~dB}$. At lower ambient temperatures the excess losses increases. This phenomenon has been observed for all channels. If we tune the temperature of the chip in an ambient temperature of $40{ }^{\circ} \mathrm{C}$ to a chip temperature of $16{ }^{\circ} \mathrm{C}$, whereby 
the target wavelength of $1554.2 \mathrm{~nm}$ is matched, the total losses are the same as the total losses at the initial temperature of $40{ }^{\circ} \mathrm{C}$. If we heat up the chip temperature to $16^{\circ} \mathrm{C}$ in an ambient temperature of $5^{\circ} \mathrm{C}$, the total losses are the same as the losses at an ambient temperature of $5{ }^{\circ} \mathrm{C}$, namely 29.6 $\mathrm{dB}$. We attribute the loss increase at lower temperature to the mismatch in thermal expansion coefficients of the invar base plate, the nylon isolating spacers and the stainless steel screws.

\section{CONCLUSION}

The commercially available single-lensed tapered fibers used in the package exhibit an eccentricity with a maximum measured value of $2 \mu \mathrm{m}$. After eccentricity measurements on each tapered fiber, fiber arrays are assembled on the Vgroove with a minimal eccentricity distribution. A measured eccentricity distribution of less than $0.5 \mu \mathrm{m}$ is observed. With a curvature radius of $14 \mu \mathrm{m}$, we have enough space for achieving optimum coupling and preventing damage during alignment and assembly procedure at one hand while maintaining sufficient coupling efficiency at the other hand. The coupling loss of the tapered fiber to a waveguide of $3 \mu \mathrm{m}$ $\times 0.6 \mu \mathrm{m}$ is approximately $5 \mathrm{~dB}$, which is almost the same as the minimum theoretical loss due to the mismatch of the fields of the taper and the chip. A best excess loss of 23.7 $\mathrm{dB}$ has been measured for the TE-mode. The cross-connect features a polarization dependence of approximately $3.1 \mathrm{~dB}$. The PHASAR of the integrated cross-connect match the target wavelengths of $1551.1,1554.2,1557.4$, and $1560.6 \mathrm{~nm}$ if the temperature of the chip is tuned to $16{ }^{\circ} \mathrm{C}$. The thermoelectric cooler with a heat pumping capacity of $3.2 \mathrm{~W}$ is sufficient to cool the chip on the invar carrier down to $16^{\circ} \mathrm{C}$ in an ambient temperature of $45^{\circ} \mathrm{C}$ or heat the chip to $16^{\circ} \mathrm{C}$ in an ambient temperature of $5{ }^{\circ} \mathrm{C}$. A higher ambient temperature range was not chosen to protect the device from lasting damage. The chip temperature can be cooled down or heated up with 25 ${ }^{\circ} \mathrm{C}$ by an electrical power of less than $1 \mathrm{~W}$. The device has a temperature dependent wavelength shift of $0.12 \mathrm{~nm} /{ }^{\circ} \mathrm{C}$. The measured tunable range is $6 \mathrm{~nm}$. In the temperature range of $20-45{ }^{\circ} \mathrm{C}$ the excess losses of the device remain constant. At lower ambient temperatures, higher excess losses are observed. In future concepts, this can be avoided by proper material choices. The typical values of back-reflection of all input and output ports are better than $-29 \mathrm{~dB}$.

\section{ACKNOWLEDGMENT}

The authors acknowledge P. W. van den Hoogen for the design and realization of the alignment tool, destined for the fiber array to chip alignment.

\section{REFERENCES}

[1] C. G. P. Herben, C. G. M. Vreeburg, D. H. P. Maat, X. J. M. Leijtens, Y. S. Oei, F. H. Groen, J. W. Pedersen, P. Demeester, and M. K. Smit, "A compact integrated InP-based single-phasar optical crossconnect," in IEEE Photon. Technol. Lett., vol. 10, pp. 678-680, May 1998.

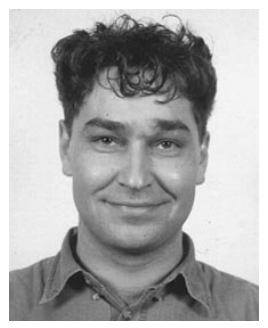

Johan H. C. van Zantvoort was born in Riethoven, The Netherlands, on November 21, 1968. He graduated in applied physics from the Technical College of Eindhoven in 1994.

He was with DAF Trucks Research, Philips Centre for Manufacturing Technology and Philips Novatronics from 1994 to 1996, consecutively. One of the activities he worked on while at DAF Trucks Research was a realization of an optical transmission link between a test truck and control panel destined for EMC measurements. At the Philips Centre for Manufacturing Technology, he was engaged in flat panel technologies and at Philips Novatronics, he was Process Engineer by a photodiode assembly line for rewritable CD-ROM players. In 1996, he joined the Electro-Optical Communication Group of Eindhoven University of Technology, Eindhoven, The Netherlands, where he is involved with packaging technologies of integrated optical devices.

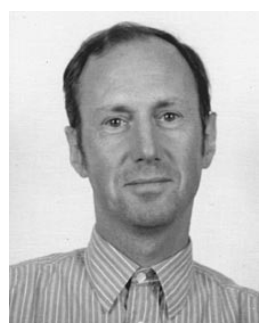

Frans M. Huijskens was born in Oudenbosch, The Netherlands, in 1958. He graduated in applied physics from the Technical College of Dordrecht in 1979.

From 1981 to 1984, he was an Electronic Test Engineer at Siemens Gammasonics. In 1985, he joined the Electro-Optical Communications Group of Eindhoven University of Technology, Eindhoven, The Netherlands. His work involved research on passive fiber couplers and support on projects concerning phase and polarization diversity coherent systems. He is currently engaged in packaging technologies of optical integrated devices and development of optical cross-connect demonstrators.

Chretien G. P. Herben was born in Sittard, The Netherlands, on October 10, 1972. He received the M.S. degree in applied physics from the University of Twente in 1996. His thesis was carried out in the Applied Optics Group and concerned the design and characterization of a scanning imaging confocal Raman microscope. Sicne December 1996, he has been working toward the Ph.D. degree at Delft University of Technology in the Photonic Integrated Circuits Group of the Faculty of Information Technology and Systems. The subject of his research concerns advanced integrated optical components for dense wavelength division multiplexed network applications with, as the main topic, the design, fabrication, and characterization of integrated optical cross-connect chips.

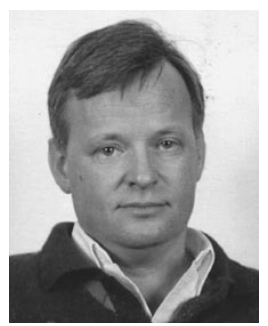

Huig de Waardt was born in Voorburg, The Netherlands, on December 1, 1953. He received the M.Sc. and Ph.D. degrees in electrical engineering from the Delft University of Technology in 1980 and 1995, respectively.

In 1981, he joined the Department of Physics, KPN Research, Leidschendam, where he was engaged in research on the performance aspects of long-wavelength semiconductor laser diodes, LED's, and photodiodes. In 1989, he moved to the Department of Transmission, where he has been working in the fields of high bit-rate direct-detection systems, optical preamplification, wavelength-division multiplexing, dispersion related system limitations, and the system application of resonant optical amplifiers. $\mathrm{He}$ contributed to (inter)national standardization bodies and to the EURO-COST activities 215 and 239. In October 1995, he was appointed as Associate Professor at the University of Eindhoven, Faculty of Electrical Engineering, in the area of high-speed trunk transmission. His current research interests are in applications of semiconductor optical amplifiers, high-speed OTDM transmission, integrated optical cross-connects, and WDM optical networking. He was active in European research programs as ACTS BLISS and ACTS Upgrade. Currently, he is responsible for the WDM system demonstrator within the ACTS APEX project. 